\title{
Long term results of pneumatic retinopexy
}

This article was published in the following Dove Press journal:

Clinical Ophthalmology

6 January 2012

Number of times this article has been viewed

\section{Amin F Ellakwa \\ Menoufiya University, Shibin el Kom, Al-Menoufiya, Egypt}

Correspondence: Amin F Ellakwa Department of Ophthalmology, Menoufiya University, Gamal Abdel Nasser Street, Shibin el Kom, Al-Menoufiya, Egypt

Tel +20 I005288543; +20 48223252 I

Email ellakwa@yahoo.com
Background: Rhegmatogenous retinal detachment is a commonly encountered retinal problem where rapid treatment can prevent irreversible vision loss. Pneumatic retinopexy (PR) is a simple, minimally invasive procedure for retinal reattachment.

Purpose: This study aimed to assess the long-term anatomical and functional outcome of pneumatic retinopexy in primary rhegmatogenous retinal detachment.

Patients and methods: A prospective interventional study was performed. Subjects with rhegmatogenous retinal detachment who underwent pneumatic retinopexy from May 2006 to May 2007 at Menoufiya University Hospital were included in this study with at least 3 years follow-up.

Results: A total of 40 cases were included in the study. The mean age of patients was $44.25 \pm 10.85$ years. Reattachment of the retina was achieved in $100 \%$ of cases. In $75 \%$ of cases, the primary intervention was successful. However, the retina redetached in $20 \%$ of these during the first 6 months, requiring reinjection or another procedure. Three years after the first intervention, follow-up measurement of the mean visual acuity of the eyes without reoperation was $0.40 \pm 0.21$ while the mean visual acuity of the eyes which needed additional operations was $0.22 \pm 0.13$.

Conclusion: Sixty percent of the cases obtained long-term retinal reattachment with a single operation success (SOS), with good visual recovery and less morbidity than other more invasive procedures like scleral buckling or pars plana vitrectomy, translating to higher productivity for the patient. This procedure, being quicker than the alternatives, also saves the surgeon's time, making PR a good choice for managing primary rhegmatogenous retinal detachment in developing countries.

Keywords: pneumatic, retinopexy, rhegmatogenous, retinal detachment

\section{Introduction}

Pneumatic retinopexy $(\mathrm{PR})$ is a minimally invasive surgical procedure in the treatment of primary rhegmatogenous retinal detachment (RRD). First introduced in the mid-1980s by Dominguez in Spain, and Hilton and Grizzard in the United States, this technique has been used in a variety of cases all over the world. ${ }^{1-3}$

There is a remarkable geographical difference in the acceptance of PR as the treatment of first choice in uncomplicated primary RRD. In Europe PR, because of its lower success rate, has not found general acceptance and is used only in selected cases. ${ }^{4}$ Two surveys were published after asking the members of the Retina Society and Vitreous Society in the United States and Canada and the members of the Retinological Society in Germany how they would manage a hypothetical 
uncomplicated primary RRD. The choices given were PR, segmental scleral buckling (SB) procedures, SB with encircling band, Lincoff balloon, and primary pars plana vitrectomy (PPV). The results of the two surveys were compared at the annual meeting of the German Ophthalmologic Society. Whereas the majority of North American responders (55\%) selected PR as their primary choice, German surgeons preferred segmental SB or SB with an encircling band as the first procedure. ${ }^{5,6}$

$\mathrm{PR}$ is an office-based procedure designed for repairing selected cases of retinal detachments. Brinton and Hilton estimated that at least $40 \%$ of RRDs can be managed by PR. ${ }^{7}$

Efficacy for repairing a retinal detachment depends on three cardinal steps: induction of retinopexy around all retinal breaks with cryopexy or laser; intraocular gas injection; and strict postoperative head positioning for an appropriate time to allow the gas tamponade to achieve closure of the retinal breaks. ${ }^{8}$

PR has become a well-accepted alternative surgical technique to SB and vitrectomy for uncomplicated RRDs with superior retinal breaks. Proponents of PR have underscored the advantages of less tissue trauma, lack of major complications, no hospitalization, and lower costs in comparison to SB and PPV. ${ }^{9}$

This study aimed to assess the long-term anatomical and functional outcome of PR in primary RRD after an average follow-up period of 3 years.

\section{Patients and methods}

This study was conducted on patients with RRD who underwent PR at Menoufiya University Hospital from May 2006 to May 2007 in a prospective interventional study. Forty patients with primary RRD due to superior retinal breaks (from 4 to 8 o'clock) were managed by intraocular injection of a large gas bubble.

Patients with proliferative vitreoretinopathy, breaks involving the lower 4 clock-hours, poorly controlled glaucoma, and dense anterior segment opacity or lack of at least 3 years follow-up were excluded from the study.

A complete ophthalmological examination was conducted including: measurement of visual acuity aided and unaided, refraction using automated refractometer, anterior segment examination using slit lamp biomicroscopy to detect any opacity, rubeosis iridis or any anterior segment abnormalities, intraocular tension measurement, and posterior segment examination using indirect ophthalmoscopy and slit lamp biomicroscopy with a three-mirror contact lens.

The patients were fully informed of the technique and the postoperative position and signed a consent form.
The procedure was performed under local anesthesia. Anterior chamber paracentesis was performed using a 27 gauge needle on an insulin syringe without the plunger, draining around $0.1-0.2 \mathrm{~mL}$ of aqueous humor. Perfluoropropane (C3F8) 0.3-0.4 mL gas was injected 3.5-4 mm posterior to the limbus through the inferotemporal quadrant. Patency of the central retinal artery was assessed by indirect ophthalmoscopy. Cryopexy was performed in 29 cases prior to gas injection while an Argon laser was applied in eleven cases after absorption of subretinal fluid.

The patients were instructed to lie in a semi-sitting position for 3 days after the procedure to allow absorption of subretinal fluid.

Patients were examined on the next postoperative day. Follow-up of the patients was continued for 3 years: every month in the first 6 months, then every 3 months after that. Results were collected, tabulated, and statistically analyzed using SPSS (v 19, IBM, Armonk, NY).

\section{Results}

The author evaluated the long-term outcome (at least 3 years) of retinal reattachment by PR. Forty eyes of 40 patients with primary RRD due to a single u-shaped break in 28 eyes $(70 \%)$ or round hole/s in twelve eyes $(30 \%)$ occupying less than 1 clock-hour of the upper quadrant of the retina were included in the study retrospectively after treatment by PR.

The patients' ages ranged from 25 to 65 years old and the mean age of patients was $44.25 \pm 10.85$ years. Seventeen patients $(42.5 \%)$ were males while 23 patients $(57.5 \%)$ were females. The average follow-up period was 3 years. Initial successful anatomical retinal reattachment after PR was obtained in $30(75 \%)$ out of 40 cases. Twenty-four cases $(60 \%)$ achieved long-term retinal reattachment with single operation success (SOS) while six cases (15\%) showed redetachment.

Two cases $(6.6 \%)$ from the patients with initial reattachment needed reinjection 1 month after the primary procedure due to reopening of the original break. They achieved long term retinal re-attachment. In four cases (13.3\%), redetachment occurred after 3 months in the first and second cases and 6 months in the third and fourth cases, due to the development of proliferative vitreoretinopathy (PVR). PPV was done to achieve reattachment, as shown in Table 1.

In ten cases $(25 \%)$, there was failure of retinal reattachment within the first month postoperatively and another procedure was needed. Four cases (10\%) needed SB and six cases (15\%) needed PPV, as shown in Table 1. 
Table I Additional procedures performed in re-operation cases

\begin{tabular}{lll}
\hline Type of procedures & Number & Percentage \\
\hline Failure of PR & 10 & $25 \%$ \\
SB & 4 & \\
PPV & 6 & \\
Redetachment after initial attachment & 6 & $15 \%$ \\
Gas re-injection & 2 & \\
PPV & 4 & \\
PR with long-term attachment & 24 & $60 \%$ \\
\hline
\end{tabular}

Abbreviations: PR, pneumatic retinopexy; SB, scleral buckling; PPV, pars plana vitrectomy.

Failure was mainly due to: the inability of the patient to maintain an adequate postoperative position for long enough (one case); reopening of the initial break (one case); the presence of missed or new retinal breaks (four cases); development of proliferative vitreoretinopathy (seven cases); or development of vitreous hemorrhage (one case), as shown in Table 2. Cryopexy was performed in 29 cases (72.5\%) prior to gas injection while Argon laser was applied in eleven cases (27.5\%) after absorption of subretinal fluid.

Looking closely at these cases, seven (17.5\%) needed further surgery due to PVR. Two of them displayed PVR grade $\mathrm{B}$, one grade $\mathrm{C} 1$, and four grade $\mathrm{C} 2$.

The final long-term reattachment at the 3-year follow up was 24 cases $(60 \%)$ with SOS. Two cases need reinjection of gas (5\%), and four cases (10\%) needed PPV. The initial failure rate was $25 \%$ (ten cases) who needed another procedure to achieve permanent retinal attachment. The overall retinal attachment was $100 \%$ at the 3 year follow-up.

Mean postoperative best corrected visual acuity (BCVA) in patients with successful reattachment by PR was $0.40 \pm 0.21$ after 3 years, while the mean postoperative BCVA in patients who required another procedure was $0.22 \pm 0.13$ at the 3 year follow-up.

The IOP was raised in eight patients with successful PR. This required medical treatment with combined beta-blocker and dorzolamide drops twice daily for 1 month.

Table 2 Causes of further operations

\begin{tabular}{ll}
\hline $\begin{array}{l}\text { Cause of redetachment after initial } \\
\text { attachment }\end{array}$ & Numbers of eyes (4) \\
\hline Inadequate position & $\mathrm{I}$ \\
Reopening of initial break & $\mathrm{I}$ \\
Proliferative vitreoretinopathy & 2 \\
Cause of failure of PR & Numbers of eyes (10) \\
Proliferative vitreoretinopathy & 5 \\
Vitreous hemorrhage & $\mathrm{I}$ \\
New/missed breaks & 4 \\
\hline
\end{tabular}

Abbreviation: $\mathrm{PR}$, pneumatic retinopexy.
Before PR, 35 eyes were phakic and 5 eyes were pseudophakic. Of the 26 cases with long-term retinal reattachment success (24 cases with SOS + two cases with gas reinjection) 25 eyes were phakic (four cases with faint cataract and 21 with clear lenses) and one eye was pseudophakic. In 14 patients who required additional procedures, there were ten phakic eyes (two cases with faint cataract and eight with clear lenses) and four pseudophakic eyes (Table 3). In the group needing additional operations, pseudophakic eyes demonstrated a higher preoperative risk of failure.

Cataracts developed in 13 cases out of 40: seven eyes out of 25 phakic eyes in patients with successful reattachment by pneumatic retinopexy, and six eyes out of ten phakic eyes in patients who required additional operations.

\section{Discussion}

Freyler and Radax ${ }^{10}$ reported their long-term results for 89 cases of retinal detachment treated with PR. They achieved primary reattachment in $73 \%$ of cases; in $12.36 \%$, redetachment occurred in five eyes $(5.6 \%)$ within the first month postoperatively and six eyes $(6.75 \%)$ within the next 5 years. Therefore, the SOS rate was $60.6 \%$. Three eyes required more than one reoperation and the final anatomic success was $100 \%$. The overall reattachment rate is comparable to that found in the present study and in other long-term studies. The SOS rate in the present study was also similar to that of Freyler and Radax ( $60 \%$ of cases). Lisle et a ${ }^{11}$ published their data on 36 eyes with an average follow-up of 8.1 years and a reported SOS rate of $83 \%$. However, they defined SOS as retinal reattachment at 6 months after surgical intervention. In three eyes, the retina redetached later than 6 months postoperatively, reducing the SOS rate to $75 \%$. The initial reattachment rate of $73 \%$ reported by Freyler and Radax is slightly lower than found in this study (75\%). However, Freyler and Radax's redetachment rate of $12.36 \%$ is lower than the $15 \%$ found in this investigation.

This study demonstrated that the risk of redetachment is highest within the first 3-6 months. Freyler and Radax ${ }^{10}$ found redetachment after initial reattachment in five eyes $(5.6 \%)$ within the first postoperative month and six eyes $(6.75 \%)$ within the next 5 years. Other showed that redetachment

Table 3 Preoperative lens status

\begin{tabular}{lll}
\hline $\begin{array}{l}\text { Preoperative lens } \\
\text { status }\end{array}$ & $\begin{array}{l}\text { Successful PR } \\
\text { (26 cases) }\end{array}$ & $\begin{array}{l}\text { PR + additional } \\
\text { operation ( I cases) }\end{array}$ \\
\hline Phakic & 25 cases (96.2\%) & I0 cases $(71.4 \%)$ \\
Pseudophakic & I case (3.8\%) & 4 cases $(28.6 \%)$ \\
\hline
\end{tabular}

Abbreviation: PR, pneumatic retinopexy. 
6 months after the initial operation is very unlikely. Tornambe and coworkers ${ }^{13}$ demonstrated the rate of redetachment beyond 6 months postoperatively to be only $1 \%$, in both eyes treated with PR and eyes treated with SB.

Looking closely at the cases in this study without SOS, seven $(17.5 \%)$ needed further surgery due to PVR. Two of them displayed PVR grade B, one grade C1, and four grade C2 according to the Retina Society classification system. ${ }^{12}$ Freyler and Radax ${ }^{10}$ described PVR in $4.5 \%$ of all their cases, corresponding to $11.4 \%$ of eyes without SOS. Throughout the study, PVR occurred as a postoperative complication in $17.5 \%$ of all cases treated with PR.

Factors influencing SOS include pseudophakia/aphakia, extent of retinal detachment and the number of retinal breaks. Tornambe ${ }^{13}$ reviewed 302 consecutive cases of PR with a follow-up of 6 months to 10 years. He found a subgroup of patients with an SOS rate of $97 \%$ with the following criteria: phakic eyes; only one quadrant of retinal detachment; only one retinal break located in the upper two-thirds of the fundus; postoperatively prophylactic $360^{\circ}$ PR. Following these strict criteria, the SOS rate of PR is comparable to that of primary SB. However, whether reoperations are necessary in PR or not does not influence the final visual outcome. Among other factors, the most important ones that influence visual recovery positively seem to be better preoperative visual acuity, preoperatively attached macula, macular detachment for less than 8 days, and younger patients. ${ }^{12}$

Preoperative lens status has been reported to be a prognostic factor for SOS. I found $96.2 \%$ of cases with PR operation success were phakic eyes and 3.8\% pseudophakic eyes. In cases with PR failure needing additional operations, I found $71.4 \%$ of the cases were phakic and $28.6 \%$ of the cases were pseudophakic. The lack of statistical significance is probably due to the small number of pseudophakic patients. Freyler and Radax ${ }^{10}$ had $4.5 \%$ pseudophakic eyes in their study, all of which needed reoperation.

Subconjunctival gas is an infrequent occurrence due to either incomplete penetration of the sclera by the needle for gas injection or outward leakage of gas through the needle track for the gas injection. No cases were recorded with this complication in the present study. Hilton et a ${ }^{14}$ reported this complication in only three eyes in a review of 1274 cases of PR. This complication is usually associated with insignificant clinical effects.

"Fish-egg" gas bubbles may migrate through retinal breaks into the subretinal space, particularly in the presence of large breaks or breaks with rigid or scrolled edges.
No cases were recorded in this study, compared with six cases reported by McDonald et al. ${ }^{15}$ Hilton et al ${ }^{14}$ indicated that any eyes with retinal breaks larger than 1 clock-hour in size are associated with an increased risk of subretinal gas after PR.

In this study, eight cases (20\%) showed raised IOP which was controlled by medical treatment without retinal or optic nerve damage. Hilton et $\mathrm{al}^{14}$ stated that with the exception of eyes with advanced or endstage glaucoma, temporary IOP elevation during or after PR usually does not lead to any retinal or optic nerve damage.

\section{Conclusion}

In a long-term follow-up study, an SOS rate of $60 \%$ was achieved with PR, a procedure that can be carried out with minimal intraoperative stress, under local anesthesia, and as an outpatient procedure. Failure after PR leads to further surgical procedures that would otherwise have been chosen as the primary intervention.

Complications such as endophthalmitis are extremely rare. PR causes minimal discomfort to the patient and carries minimal surgical risk, yet the patient has a $65 \%$ chance of achieving permanent reattachment of the retina with nothing else but this procedure.

\section{Disclosure}

The author reports no conflicts of interest in this work.

\section{References}

1. Dominguez DA. Cirugia precoz y ambulatoria del desprendimiento de retina. Arch Soc Esp Oftalmol. 1985;48:47-54. [Spanish].

2. Laqua H. Ist die Buckelchirurgie zeitgemäß. Ophthalmol Nachricht. 1999;10:20-21. [German].

3. Hilton GF, Grizzard WS. Pneumatic retinopexy. A two-step outpatient operation without conjunctival incision. Ophthalmology. 1986;93(5):626-641.

4. Hoerauf H, Heimann H, Hansen L, Laqua H. Scleral buckling surgery and pneumatic retinopexy. Techniques, indications and results. Ophthalmologe. 2008;105(1):7-18. [German].

5. Benson WE, Chan P, Sharma S, Snyder WB, Bloome MA, Birch DG. Current popularity of pneumatic retinopexy. Retina. 1999;19(3): 238-241.

6. Laqua H. Ist die Buckelchirurgie zeitgemäß. Ophthalmol Nachricht. 1999;10:20-21.

7. Brinton DA, Hilton GF. Pneumatic retinopexy and alternative retinal detachment techniques. In: Ryan SJ, Wilkinson CP, editors. Retina, Vol. 3, 3rd ed. St Louis, MO: Mosby Inc; 2001:2047-2062.

8. Chan CK, Lin SG, Nuthi AS, Salib DM. Pneumatic retinopexy for the repair of retinal detachments: a comprehensive review (1986-2007). Surv Ophthalmol. 2008;53(5):443-478.

9. Hilton GF, Das T, Majji AB, Jalali S. Pneumatic retinopexy principles and practice. Indian J Ophthalmol. 1996;44(3):131-143.

10. Freyler H, Radax U. Pneumatic retinopexy - a study of 7 years experience. Klin Monatsbl Augenheilkd. 1993;202(3):212-217. German.

11. Lisle C, Mortensen KK, Sjolie AK. Pneumatic retinopexy. A long term follow-up study. Acta Ophthalmol Scand. 1998;76(4):486-490. 
12. Retina Society Terminology Committee. The classification of retinal detachment with proliferative vitreoretinopathy. Ophthalmology. 1983; 90(2):121-125.

13. Tornambe PE. Pneumatic retinopexy: the evolution of case selection and surgical technique. A twelve-year study of 302 eyes. Trans Am Ophthalmol Soc. 1997;95:551-578.
14. Hilton GF, Tornambe PE. The Retinal Detachment Study Group: Pneumatic retinopexy. An analysis of intraoperative and postoperative complications. Retina. 1991;11(3):285-294.

15. McDonald HR, Abrams GW, Irvine AR, et al. The management of subretinal gas following attempted pneumatic retinal reattachment. Ophthalmology. 1987;94(4):319-326.

\section{Publish your work in this journal}

Clinical Ophthalmology is an international, peer-reviewed journal covering all subspecialties within ophthalmology. Key topics include: Optometry; Visual science; Pharmacology and drug therapy in eye diseases; Basic Sciences; Primary and Secondary eye care; Patient Safety and Quality of Care Improvements. This journal is indexed on

Submit your manuscript here: http://www.dovepress.com/clinical-ophthalmology-journal

\section{Dovepress}

PubMed Central and CAS, and is the official journal of The Society of Clinical Ophthalmology (SCO). The manuscript management system is completely online and includes a very quick and fair peer-review system, which is all easy to use. Visit http://www.dovepress.com/ testimonials.php to read real quotes from published authors. 